\title{
A report on the development and work of the Labor Welfare Corporation Spinal Injuries Center in Japan
}

Eiji Iwatsubo, Keiichiro Shiba, Takayoshi Ueta, Yoshiharu Takemitsu and Takashi Akatsu

The Labor Welfare Corporation Spinal Injuries Center, 550-4, Igisu, Iizuka, 820 Japan

Keywords: Spinal Injuries Center; Japan; Labor Welfare Corporation

The Labor Welfare Corporation (LWC) Spinal Injuries Center was founded by the Labor Ministry of Japan in 1979 (Figure 1). ${ }^{1}$ It consists of a twofloored building with two wards each with 75 beds, a rehabilitation engineering unit, a vocational rehabilitation unit with workshop, a gymnasium, an outdoor pool, a greenhouse, tennis courts and a heliport, constructed on an area of ground of 82000 yard $^{2}$ with 18 million dollars of financial expenditure. It was mainly designed by Dr Tamikazu Amako for an integrated and specialized center for patients with spinal cord injury. There is a staff of 140 for 150 beds: 18 are medical doctors (13 orthopaedic, three urology, one rehabilitation, and one internal medicine), 84 nurses (79 registered nurses and five nurse aids), 11 rehabilitation staff (6 PTs and 5 OTs), one medical social worker, five medical engineering staff, three pharmacists, one dietician, five laboratory and four radiological technicians, 16 clerks and one driver. One third of the 150 beds are for acute patients with spinal cord injury and the remainder are for patients with spinal disease and trauma with or without paralysis. Our service covers the western part of Japan, mainly the Kyushu island area (Figure 2). We had 208

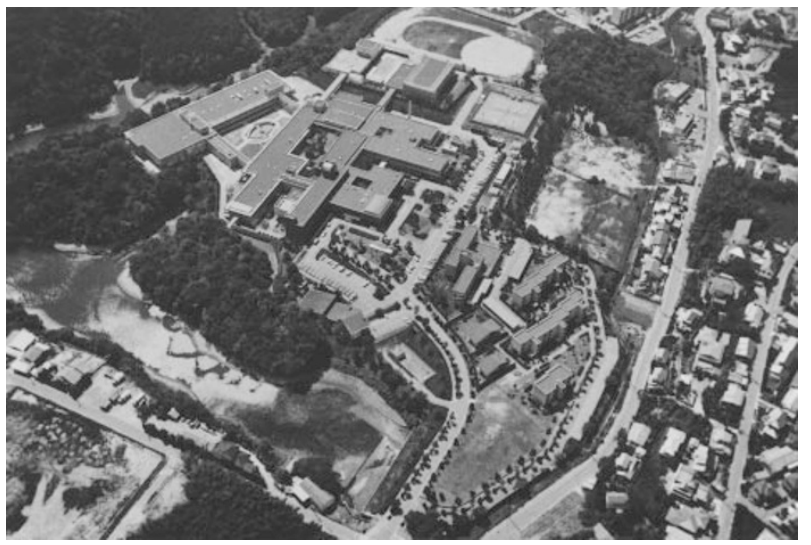

Figure 1 The bird's eye view of the LWC Spinal Injuries Center

Correspondence: E Iwatsubo inpatients and 2883 outpatients in 1993; of which 165 $(79 \%)$ and $2655(92 \%)$ were from Fukuoka prefecture, respectively. This prefecture covers $5000 \mathrm{~km}^{2}$ with a population of 6 million. For the past 15 years, 47 patients were transported by helicopters of the SelfDefense-Force; and 13 came from outside Japan (Australia and North Korea), Hokkaido, Tokyo and Okinawa by fixed wing aircraft. From 1979-1993, 980 new patients (831 males and 149 females) with spinal cord injury were hospitalized. For the first 5 years, every patient with spinal cord injury who came to our center had spinal surgery to permit earlier ambulation and rehabilitation, but subsequently surgical measures are less, and conservative treatment has been increasing. Seven hundred and eighty patients had a cervical cord injury, 195 thoracolumbar or caudal, and 5 had an unknown lesion. The main causes of injury

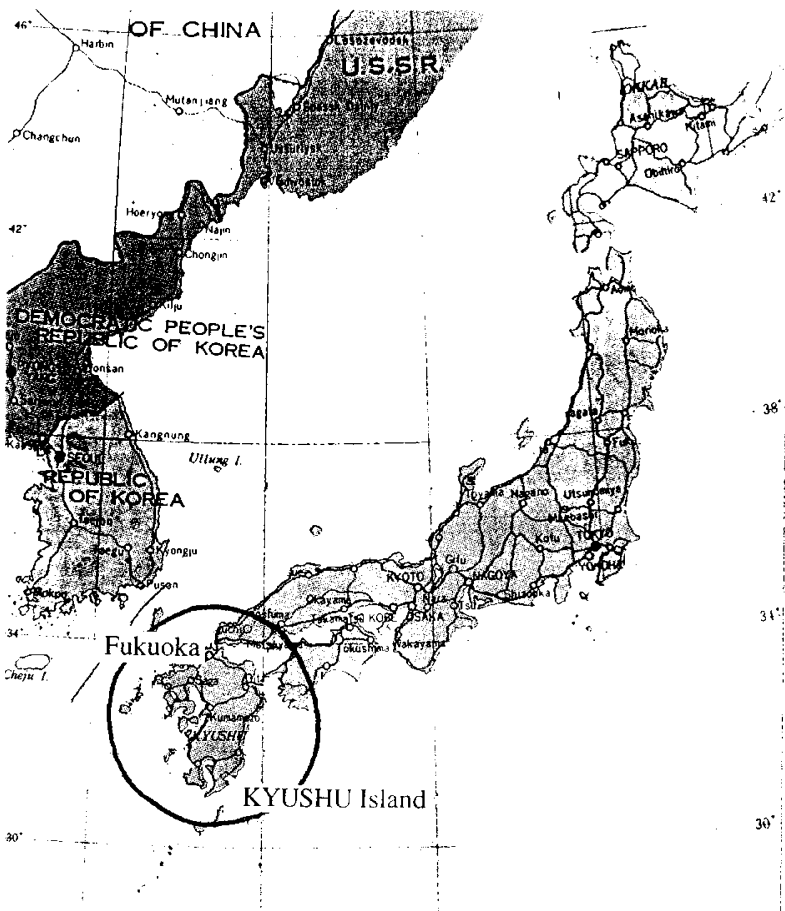

Figure 2 The area covered by the LWC Spinal Injuries Center 
Table 1 Epidemiology of spinal cord injury in Japan

\begin{tabular}{lcc}
\hline & $\begin{array}{c}\text { LWC SIC } \\
1979-1993(\%)\end{array}$ & $\begin{array}{c}\text { Whole Japan } \\
1990-1992(\%)\end{array}$ \\
\hline Male & $831(84.8)$ & $7842(80.4)$ \\
Female & $149(15.2)$ & $1909(19.6)$ \\
Cervical cord lesion & $780(79.6)$ & $7317(75.0)$ \\
Thoracolumbar & $195(19.9)$ & $2408(24.7)$ \\
Unknown & $5(0.5)$ & $27(0.3)$ \\
Traffic accident & $398(40.6)$ & $4263(43.7)$ \\
Fall from a height & $273(27.9)$ & $2818(28.9)$ \\
Fall on even ground & $72(7.4)$ & $1260(12.9)$ \\
Struck by object & $62(6.3)$ & $537(5.5)$ \\
Sport injury & $66(6.7)$ & $528(5.4)$ \\
Other causes & $109(11.1)$ & $346(3.6)$ \\
\hline
\end{tabular}

were 398 traffic accidents $(40.6 \%), 273$ falls from a height $(27.9 \%), 66$ sports related injuries $(6.7 \%), 62$ struck by a falling object $(6.3 \%), 72$ falls on even ground $(7.4 \%)$ and 109 had unknown causes $(11.1 \%)$. The causes for spinal cord injury in our patients correlates with the report of the nation wide epidemiological survey in Japan (Table 1$)^{2}$

Aseptic intermittent catheterization was the standard care for acute urinary retention. Regular catheterization four or five times a day under restricted fluid intake for every patient with an incomplete cord lesion and for every tetraplegic male patient was the rule for good future voiding; catheterization twice a day without fluid restriction, was the rule for every paraplegic patient with a complete cord lesion for future self-catheterization. ${ }^{3}$ This regimen has been approved for payment by medical insurance policy in Japan since 1994. About $20 \%$ of patients with a spinal cord injury are discharged free from a urological complaint, $30 \%$ with self-catheterization, $45 \%$ with the use of an external condom, and the remainder, mainly female, were discharged with a cystostomy catheter. In the annual report of our center we announced that the hospitalization period was from 122 to 70 days, with an average of 97 days for all inpatients, and from 190 to 108 days, with an average of 140 days for inpatients with a spinal cord injury. In general, a person with paraplegia was discharged within 6 months, and those with tetraplegia within a year. The main reason for the delay of discharge is not a medical one, but is due to a housing problem. The Japanese life style is not suitable for paralysed people who depend on the use of a wheelchair. The LWC Spinal Injuries Center has received many visitors and guests of medical personnel from Korea, China, Thailand and from the other countries in Asia in view of it being a specialized Center for patients with disease or injury of the spine and the spinal cord causing spinal paralysis.

\section{References}

1 Akatsu T. A new spinal injuries center at Iizuka city in Japan. Paraplegia 1982; 20: 313 - 314.

2 Hikosuke S. A Nationwide epidemiological survey of spinal cord injuries in Japan from January 1990 to December 1992 Prevention Committee of Japan Medical Society of Paraplegia 1994; 6: $1-32$.

3 Iwatsubo E et al. Over-distension therapy of the bladder in paraplegic patients using self-catheterisation: A preliminary study. Paraplegia 1984; 22: 210-215. 